\title{
Association between antipsychotics and cardiovascular adverse events: A systematic review
}

Ana Amancio Santos Da Silva ${ }^{1 *}$, Marina Viegas Moura Rezende Ribeiro ${ }^{1}$, Célio Fernando de Sousa-Rodrigues ${ }^{2}$, FABIANo Timbó BARBosa ${ }^{3}$

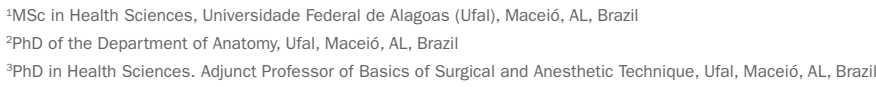

Keywords: antipsychotics, cardiovascular diseases, schizophrenia.

\section{INTRODUCTION}

Schizophrenia is a chronic mental illness that occurs in approximately $1 \%$ of the population, including about 3 million in the United States. ${ }^{1}$ Epidemiology in Brazil is similar to data found in other countries. ${ }^{2}$ Despite the relatively high prevalence of schizophrenia, data correlating risk factors and cardiovascular disease mortality are scarce. ${ }^{3}$

The symptoms of schizophrenia emerge in adolescence or early adulthood and can be classified into symptoms: positive or psychotic (delusions and hallucinations), negative (blunted affect) and disorganization (conceptual disorganization of thought, bizarre behavior). ${ }^{3}$

Individuals with schizophrenia have their life expectancy shortened by about $20 \%$ in the general population and are more vulnerable to other diseases such as diabetes, coronary heart disease, hypertension and emphysema.,

Cardiovascular disease is the leading cause of death among schizophrenics being responsible for 17.3 million deaths per year, a number that is expected to increase to 23.6 million in 2030. ${ }^{6}, 7$ In Brazil, it accounts for $20 \%$ of all deaths in individuals over 30 years, being one of the main causes of mortality. ${ }^{8}$

Some studies suggest that mortality from cardiovascular disease may be increasing in schizophrenic patients compared with the general population..$^{9,10}$ There is controversy about the association between cardiovascular adverse events and the use of antipsychotic agents. This review aimed to assess whether there is a risk.

\section{Method}

We adopted the Preferred Reporting Items for Systematic Reviews and Meta-Analyses (PRISMA) ${ }^{11}$ recommendations in this systematic review.

The Protocol was recorded and published prior to this research in the International Prospective Register of Systematic Reviews (PROSPERO http://www.crd.york.ac.uk/ PROSPERO/display_record.asp?ID=CRD42015024719). 
Scientific articles were selected from the following databases: Latin Literature American and Caribbean Health Sciences (LILACS), PubMed (via MEDLINE), The Cochrane Controlled Clinical Trials Database (CENTRAL) and PsycINFO from the start of each database up to November 2015. The search strategy for PubMed was the query: ("antipsychotic agents" [Pharmacological Action] OR "antipsychotic agents" [MeSH Terms] OR ("antipsychotic" [All Fields] "), ("agents "[All Fields]) OR" antipsychotic agents "[All Fields]), ("mental disorders" [MeSH Terms] OR ("mental" [All Fields] AND "disorders" [All Fields]) OR "mental disorders" [All Fields] OR ("mental" [All Fields] AND "illness" [ All Fields]) OR "mental illness" [All Fields] OR "schizophrenia" [MeSH Terms] OR "schizophrenia" [All Fields]), ("heart diseases" [MeSH Terms] OR ("heart" [All Fields] AND "diseases" [All Fields]) OR "heart diseases" [All Fields] OR ("cardiac" [All Fields] AND "disease" [All Fields]) OR "cardiac disease" [All Fields]). Searches in other databases were similar. Manual searches in the references of original articles selected were carried out, and new original articles which met the inclusion criteria were included.

Eligibility criteria were: original articles from observational studies that evaluated the cardiovascular adverse effects and the use of antipsychotic drugs, typical and atypical, in adult patients with schizophrenia. The original articles compared antipsychotic treatment either versus lack of therapy, or a placebo, or an alternative medication. There was no restriction of sex, ethnicity, color or comorbidity.

Exclusion criteria were: original articles from observational studies with incomplete description of data related to the variables, original articles published in more than one original database, and articles whose treatment had not been properly described.

According to the eligibility criteria, two reviewers (AASS and MVMRR) were selected independently to analyze titles and abstracts. Whenever the summary did not provide enough information, the articles were partially assessed to determine their eligibility, with the author being questioned in case any information was missing. Observational scientific articles that met the criteria were read in its entirety. The reference list of the articles included was analyzed for items not found in the databases. Disagreements between reviewers were resolved by discussion.

The extraction of data from observational articles was performed using a standardized instrument by the authors containing the following information: method, participants (number of participants, the inclusion criteria, exclusion criteria, age, gender (male / female) and group intervention (risk factor), control group (risk factor), primary variables, secondary variables, objective, types of drugs, confounding details, follow-up and notes).

The articles were evaluated in order to determine their primary variables: cardiac arrest, congestive heart failure, arrhythmias, myocardial ischemia, and acute myocardial infarction. Secondary variables were: mortality and quality of life. The results evaluated were: mean, standard deviation, frequency, prevalence as well as the p-values and effect of measures, such as relative risk and odds ratio.

This research included items that underwent methodological critical assessment as recommended by the Cochrane risk of bias: A rating scale Newcastle-Ottawa (ON) for observational studies. ${ }^{12}$ This rating scale Newcastle-Ottawa has three dimensions: Selection, comparison and exposure (case-control studies) and selection, comparison and outcomes (cohort studies). In each dimension, there are answers that highlight the best quality, which is ranked with a star. A score equal to or less than 6 stars indicates poor methodological quality. A score of 6 or 7 indicates good methodological quality. An 8 or 9 score indicates very good methodological quality. ${ }^{12}$ In this review, two reviewers (AASS and MVMRR) assessed trial quality independently and disagreements were resolved by consensus building.

\section{RESULTS}

\section{Selection study}

This research identified 2,808 publication titles and summaries, from which 2,741 articles were eliminated after reading of summaries. A total of 71 articles were considered potentially relevant and were read in full, but 15 were excluded due to inadequate population, five due to inadequate type of study, 34 due to inadequate type of intervention, eight because the control group was inadequate and six because the variables were irrelevant. Duplication of scientific articles, which also had inadequate control groups, were eliminated. ${ }^{13,14}$ In all, three articles (articles $1,{ }^{15} 2,{ }^{16}$ and $3^{17}$ ) met the inclusion criteria and were considered relevant, thus being qualitatively analyzed (Figure 1).

\section{Characteristics of studies}

Table 1 shows the characteristics of the studies included in this systematic review. Data from 403,083 patients with schizophrenia and 119,015 participants in the control group were analyzed. The authors of article 1 noted that $1,912(63.5 \%)$ patients in the schizophrenic group $(3,022)$ had cardiovascular disease, as well as 5,584 (46.2\%) in the control group $(12,088) \cdot{ }^{15}$ In article 2 , they found eight (13.1\%) patients in the schizophrenia group (61) who had heart disease, and 53 (86.9\%) who had no cardiovascular 


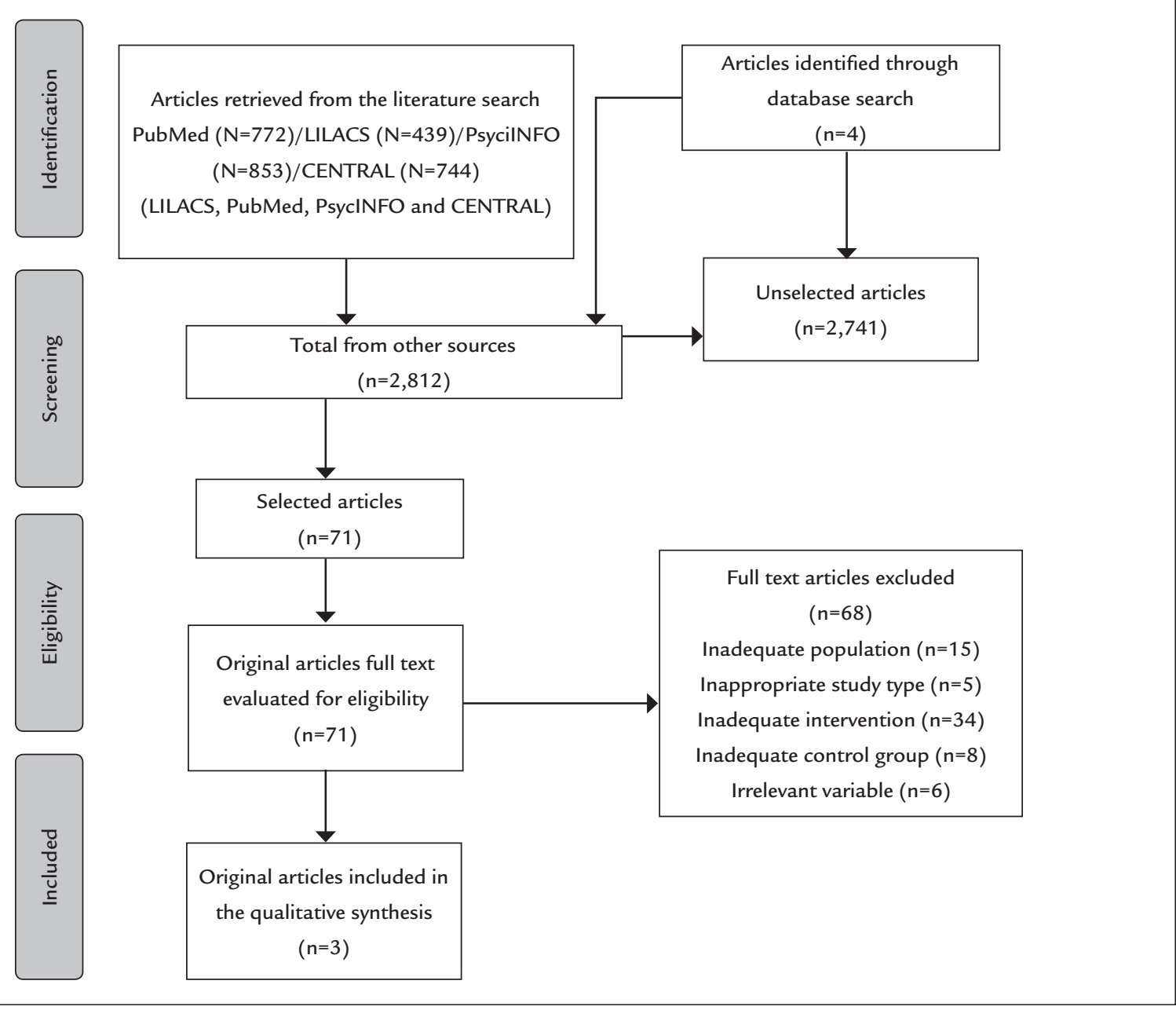

FIGURE 1 Flowchart of the search strategy.

disease; 857 (12.4\%) control patients (6927) had cardiovascular disease. ${ }^{16}$ Article 3 conducted a cohort model to estimate the risk of cardiac events in patients with schizophrenia, with 400,000 patients in schizophrenia group, of which $99,823(24.95 \%)$ had cardiovascular disease, whereas $24,900(24.9 \%)$ in the control group $(100,000)$ had cardiovascular disease. ${ }^{17}$

One study (article 1) was conducted in Saskatchewan, Canada ${ }^{15}$ and other two in Spain (article 2) ${ }^{16}$ and Finland (article 3). ${ }^{17}$ The three articles were cohort studies. There was clinical heterogeneity between them. According to the Newcastle-Ottawa Scale that assesses the methodological quality, the articles demonstrated high risk of bias Table 2 .

Measures cardiovascular adverse events associated with treatment with antipsychotics

An article (article 1) defined the cases of arrhythmia and myocardial infarction in accordance with the provisions of
ICD 9. ${ }^{15}$ Another article (article 2) included diagnoses of acute myocardial infarction based on electrocardiogram, health check and information records. ${ }^{16}$ And the last article (article 3 ) included mortality data due to cardiovascular events based on the Anglo-Scandinavian Cardiac Outcomes Trial (ASCOT-BPLA). ${ }^{17}$

\section{Variables}

Primary variables

Cardiopulmonary arrest (CPA) associated with the use of antipsychotic agents

"Cardiopulmonary resuscitation" had not been reported in any of the original articles included.

Congestive heart failure (CHF) associated with the use of antipsychotic agents

"Congestive heart failure" had not been described in any of the original articles included. 


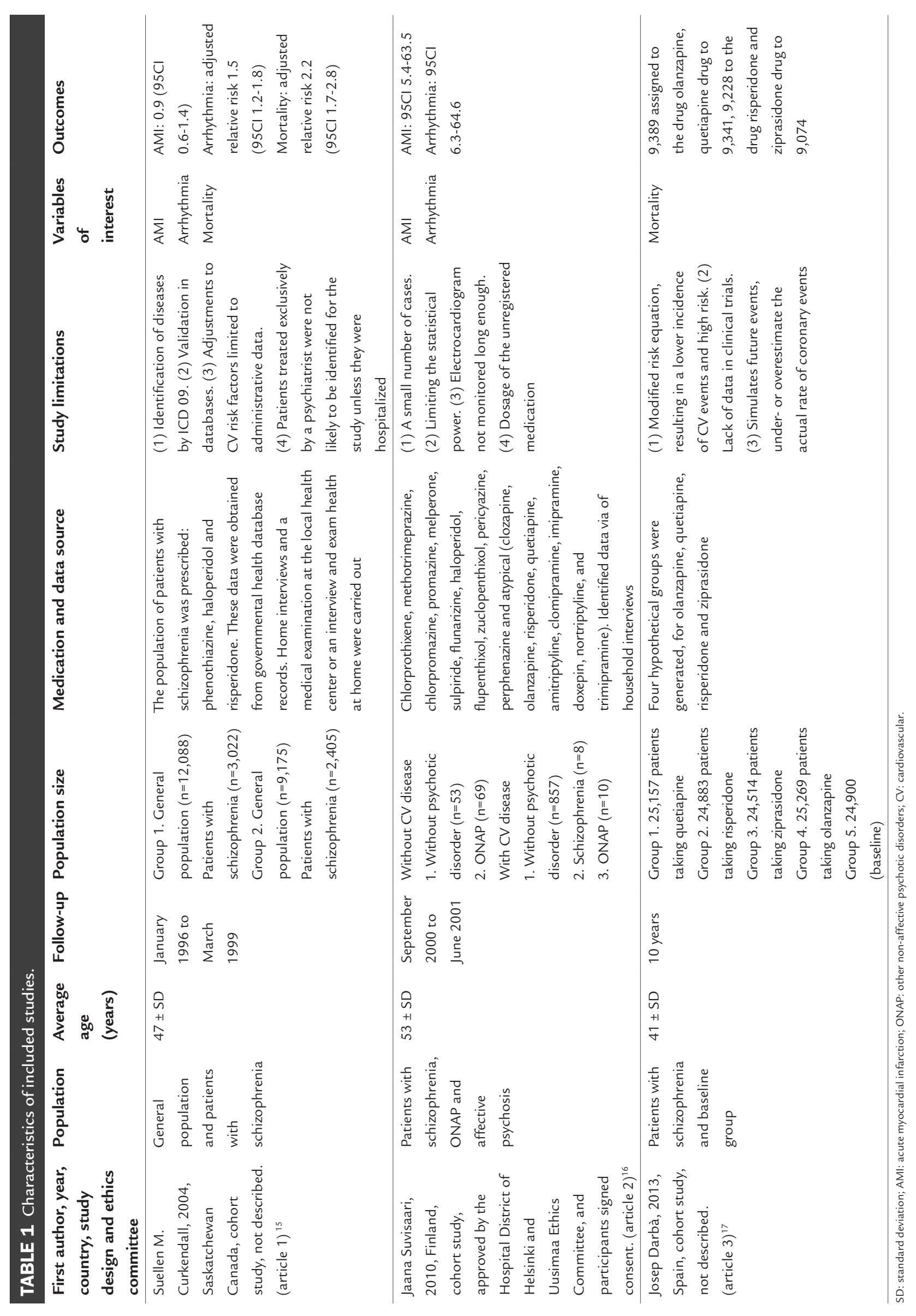


TABLE 2 Assessment of methodological quality using Newcastle-Ottawa ladder.

\begin{tabular}{llll} 
Author/year & Selection & Comparison & Result \\
\hline Curkendall et al., $2004(\text { article } 1)^{15}$ & $* *$ & $*$ & $*$ \\
\hline Suvisaari et al., $2010(\text { article } 2)^{16}$ & $*$ & $*$ & $*$ \\
\hline Darbà et al., 2013 (article 3) & $* *$ & $*$ & 0 \\
\hline
\end{tabular}

Notice:

1. Selection, comparison and results were evaluated in the cohort studies.

All items that are not as described receive a score of 0 (zero) points. One star means a quality point. A score equal to or less than 6 indicates high risk of bias.

Arrhythmia associated with the use of antipsychotic agents

Arrhythmia was assessed in two articles. In an original article (article 2), ${ }^{16} 25.9 \%$ (535) of schizophrenics (95CI 6.3-64.6) who used antipsychotics showed arrhythmia compared to groups without psychotic disorder or other non-affective psychotic disorders (ONAP). The meta-analysis of this variable could not be performed due to the fact that one of the studies ${ }^{16}$ used, as a control group, patients with other psychoaffective diseases.

The other article (article 1) showed the following data: population of schizophrenics $(155 / 3,022)$ and control (443/12,088), adjusted relative risk 1.5 (95CI 1.2-1.8), demonstrating a significant increase in arrhythmia associated with the use of antipsychotic agents compared to the general population not taking antipsychotics. ${ }^{15}$

Myocardial ischemia associated with the use of antipsychotic agents No articles were identified that evaluated the variable "myocardial ischemia" (coronary heart disease without necrosis) versus use of antipsychotics.

Acute myocardial infarction (AMI) associated with the use of antipsychotic agents

We identified two articles that reported AMI. In an original article (article 2), 24.0\% of AMI was associated with the use of antipsychotics in schizophrenia (95CI 5.4-63.5) compared to groups that did not have psychotic disorder and ONAP. ${ }^{16}$ A meta-analysis of this variable could not be performed due to the fact that one of the studies ${ }^{16}$ used, as a control group, patients with other psychoaffective diseases.

In another article, the data on the prevalence of AMI had the following results: with adjusted relative risk of 1.3 (95CI 0.9-1.9), there was no significant difference between the group with schizophrenia and the control group not taking antipsychotic agents. But the data on the incidence of AMI in a population of schizophrenic $(103 / 2,405)$ and control $(459 / 9,175)$ individuals with adjusted relative risk of 0.9 (95CI 0.6-1.4) showed a significant increase of AMI in the schizophrenia group compared to the control group that did not use antipsychotic agents. ${ }^{15}$ It was not possible to perform meta- -analysis of these data because we did not find another study with quantitative data for comparison.

\section{Secondary variables}

Mortality associated with the use of antipsychotic agents

Mortality was described in two articles. The first reported mortality due to cardiac events with 9,389 attributed to olanzapine, 9,341 to quetiapine, 9,228 to risperidone and 9,074 to ziprasidone. ${ }^{17}$ A meta-analysis could not be performed for this variable due to the fact that the authors ${ }^{17}$ did not specify the control group. We have requested information from the author by email, but to date we have received no response.

The second article identified the data on mortality from cardiovascular disease, displayed in this systematic review mode as provisional results, as follows: adjusted relative risk 2.2 (95CI 1.7-2.8), demonstrating a significant increase in mortality associated with the use of antipsychotic agents compared to the general population that does not take antipsychotic agents. ${ }^{15}$ It was not possible to perform meta-analysis of these data because we did not find another study with quantitative data for comparison.

Quality of life associated with the use of antipsychotic agents Quality of life has not been described in any of papers included.

\section{Risk of bias in articles}

The three ${ }^{15-17}$ articles (articles 1, 2, and 3) were classified as being at high risk of bias, the evidence generated is currently insufficient to determine an association between cardiovascular adverse events and the use of antipsychotic agents. The quality of evidence of a systematic review of studies with high or intermediate risk of bias can be classified as very low, due to studies being conducted with poor quality.

\section{Discussion}

Schizophrenia is a chronic psychosis that causes changes in thinking, emotions and behavior. It has a different set of signs and symptoms, characterizing a clinical syndrome. ${ }^{18,19}$ 
Pharmacological treatment for schizophrenia is the use of antipsychotics (also known as neuroleptics, antipsychotic drugs or major tranquillizers). ${ }^{20}$ Antipsychotic drugs are classified into two groups: first generation, typical or conventional, and second-generation, or atypical. ${ }^{20}$ The differences between groups are not precisely clarified, but it is believed that it depends on the profile of receptors, the incidence of extrapyramidal side effects, and efficacy. ${ }^{20}$

Studies have shown increased risk of developing cardiovascular disease with the use of antipsychotics in schizophrenic patients, since mortality in these patients compared to the general population is two to three times higher. ${ }^{9,21,22}$ It becomes worthwhile to know if there is an association between use of antipsychotics and the risk of adverse cardiovascular events.

The articles included in our systematic review were cohort studies and it is difficult to confirm causality in these studies. Limitations of our review include: the fact Suvisaari et al. (article 2$)^{16}$ used, as a control group, patients with other psychoaffective diseases; Darbà et al. (article 3) ${ }^{17}$ not specifying what was their control group, and the absence of e-mail replies sent to the authors regarding part of the data. These limitations provided a provisional result of this systematic review and it is not possible to perform a meta-analysis. Other limitations included: scientific papers reporting on mortality in schizophrenia without associating it with the use of antipsychotics, and reporting on mortality in schizophrenia, but not specifying which cardiovascular disease they have caused. In addition to the lack of identification of randomized controlled trials, there were distinct populations across studies, and variability in antipsychotics and sample sizes.

The definitions used to identify cases of arrhythmia, acute myocardial infarction and mortality differed widely. Consequently, there was a great clinical heterogeneity due to diagnostic criteria. Curkendall et al. (article 1$)^{15}$ included cases of arrhythmia and myocardial infarction incidence and prevalence data and, in cases of mortality, only incidence data.

Not only did all the studies evaluate very heterogeneous populations, but they also used different record sources and various types of antipsychotics. In the study by Curkendall et al. (article 1), ${ }^{15}$ patients were prescribed phenothiazines, haloperidol and risperidone. In the article by Suvisaari et al. (article 2), ${ }^{16}$ schizophrenics used high potency antipsychotics, low power and atypical antipsychotics. In the article by Darbà et al. (article 3) ${ }_{1}^{17}$ patients used olanzapine, quetiapine, risperidone and ziprasidone. None of the three studies ${ }^{15-17}$ reported information on: follow-up time while using antipsychotic drugs, dosage of antipsy- chotics, interruption or changes in medication, and if there was any cumulative exposure of other drugs.

An observational cohort study aimed to identify whether arrhythmia was associated with the use of antipsychotics, revealing that patients with schizophrenia who used antipsychotics had higher rates of ventricular arrhythmia than the control group. Although this study corroborates the data in our systematic review, we did not include it in our analysis because both the control group and the experimental group were treated with antipsychotics. ${ }^{24} \mathrm{An}$ other study of the cohort reported that there was a higher prevalence of arrhythmias in patients with schizophrenia compared with patients without schizophrenia. ${ }^{25}$

Our data corroborate the data of another systematic review that investigated a similar association but also found clinical heterogeneity among the studies included, leading to an inconclusive answer to the controversy regarding the use of antipsychotics associated with risk of myocardial infarction in adults. ${ }^{23}$

The implication for clinical practice is that psychiatrists should be alert to patients who use antipsychotic drugs for possible heart disease, periodically searching for information in order to prevent these diseases. The physician should make a critical analysis and evaluate the advantages, disadvantages and limitations of the use of antipsychotics in order to choose the best suited antipsychotic drug with the lowest possible risk.

\section{Conclusion}

Our systematic review found that the use of antipsychotic agents was associated with an increased risk of cardiovascular adverse events (arrhythmia, acute myocardial infarction and mortality) in schizophrenic patients. ${ }^{15-17}$ However, these results are not definitive and the question remains until further studies with appropriate research design and sufficient sample can shed light on the matter.

\section{Conflict of interest}

The authors declare no conflict of interest.

\section{Resumo}

Associação entre antipsicóticos e eventos adversos cardiovasculares: uma revisão sistemática

Objetivo: Determinar se existe associação entre o risco de eventos adversos cardiovasculares e o uso de agentes antipsicóticos.

Método: Análise de artigos originais identificados pelas bases de dados: Lilacs, PubMed, Cochrane Controlled Trials 
Banco de Dados Clínicos (CENTRAL) e PsycINFO, sem restrição de idiomas, foi realizada até novembro de 2015. Depois da triagem de 2.812 estudos, três artigos originais tipo coorte foram selecionados para análise de qualidade. Resultados: Foram analisados dados de 403.083 pacientes com esquizofrenia e 119.015 participantes do grupo controle. A ocorrência de eventos cardiovasculares observados nos artigos foi: $63,5 \%$ (artigo 1), 13,1\% (artigo 2), 24,95\% (artigo 3) nos grupos de esquizofrênicos tratados e, respectivamente, $46,2 \%, 86,9 \%$ e $24,9 \%$, nos grupos controle. Conclusão: A heterogeneidade clínica entre os estudos levou a uma resposta provisória e impossibilitou a execução da metanálise, apesar de os artigos demonstrarem associação entre eventos adversos cardiovasculares e uso de antipsicóticos. São necessários mais ensaios clínicos de qualidade para sustentar essa evidência.

Palavras-chave: antipsicóticos, doenças cardiovasculares, esquizofrenia.

\section{References}

1. Hennekens CH, Hennekens AR, Hollar D, Casey DE. Schizophrenia and increased risks of cardiovascular disease. Am Heart J. 2005; 150(6):1115-21.

2. Mari JJ, Leitão RJ. [The epidemiology of schizophrenia]. Braz J Psychiatry. 2000; 22(Suppl I):15-7.

3. Fallin MD, Lasseter VK, Avramopoulos D, Nicodemus KK, Wolyniec PS, McGrath JA, et al. Bipolar I disorder and schizophrenia: a 440-singlenucleotide polymorphism screen of 64 candidate genes among Ashkenazi Jewish case-parent trios. Am J Hum Genet. 2005; 77(6):918-36

4. Marder SR, Essock SM, Miller AL, Buchanan RW, Casey DE, Davis JM, et al. Physical health monitoring of patients with schizophrenia. Am J Psychiatry. $2004 ; 161(8): 1334-9$

5. Newman SC, Bland RC. Mortality in a cohort of patients with schizophrenia: a record linkage study. Can J Psychiatry. 1991; 36(4):239-45.

6. American Heart Association. Heart Disease and Stroke Statistics - At-aGlance; 2015 [cited 2015 Dec 5]. Available from: https://www.heart.org/idc/ groups/ahamah-public/@wcm/@sop/@smd/documents/downloadable/ ucm_470704.pdf

7. American Heart Association. What is cardiovascular disease? 2015 [cited 2015 Dec 5]. Available from: http://www.heart.org/HEARTORG/Caregiver/ Resources/WhatisCardiovascularDisease/What-is-Cardiovascular-disease UCM_301852_Article.jsp\#.VmK7_fzIYfQ.
8. Mansur AP, Favarato D. Mortality from cardiovascular disease in Brazil and in the metropolitan region of São Paulo: update 2011. Arq Bras Cardiol. 2012; 99(2):755-61.

9. Osby U, Correia N, Brandt L, Ekbom A, Sparén P. Mortality and causes of death in schizophrenia in Stockholm country, Sweden. Schizophr Res. 2000; 45(1-2):21-8

10. Goff DC, Sullivan LM, McEvoy JP, Meyer JM, Nasrallah HA, Daumit GL, et al A comparison of ten-year cardiac risk estimates in schizophrenia patients from the CATIE study and matched controls. Schizophr Res. 2005; 80(1):45-53.

11. Moher D, Shamseer L, Clarke M, Ghersi D, Liberati A, Petticrew M, et al. Preferred reporting items for systematic review and meta-analysis protocols (PRISMA-P) 2015 statement. Syst Rev. 2015; 4:1.

12. Wells GA, de Sousa MR, Fereguetti TO, Rabello A. The Newcastle-Ottawa Scale (NOS) for assessing the quality of non-randomized studies in metaanalyzes; 2000. Available from: http://www.ohri.ca/programs/clinical_ epidemiology/oxford.asp

13. Kelly DL, McMahon RP, Wehring HJ, Liu F, Mackowick KM, Boggs DL, et al. Cigarette smoking and mortality risk in people with schizophrenia. Schizophr Bull. 2011; 37(4):832-8.

14. Kelly DL, McMahon RP, Liu F, Love RC, Wehring HJ, Shim JC, et al Cardiovascular disease mortality in chronic schizophrenia patients treated with clozapine. J Clin Psychiatry. 2010; 71(3):304-11.

15. Curkendall SM, Mo J, Glasser DB, Rose Stang M, Jones JK. Cardiovascular disease in patients with schizophrenia in Saskatchewan, Canada. J Clin Psychiatry. 2004; 65(5):715-20.

16. Suvisaari J, Perälä J, Saarni SI, Kattainen A, Lönnqvist J, Reunanen A. Coronary heart disease and cardiac conduction abnormalities in persons with psychotic disorders in the general population. Psychiatry Res. 2010; 175(1-2):126-32.

17. Darbà J, Kaskens L, Aranda P, Arango C, Bobes J, Carmena R, et al. The simulation model to estimate 10 -year risk of coronary heart disease events in patients with schizophrenia spectrum disorders treated with secondgeneration antipsychotic drugs. Ann Clin Psychiatry. 2013; 25(1):17-26.

18. Silva RCB. [Schizophrenia: a review]. USP Psychol. 2006;17(4):263-85.

19. Carlborg A, Winnerbäck K, Jönsson EG, Jokinen J, Nordström P. Suicide in schizophrenia. Expert Rev Neurother. 2010; 10(7):1153-64.

20. Rang HP, Dale MM. Rang and Dale's pharmacology. Edinburgh: Elsevier Churchill Livingstone Elsevier; 2012.

21. Saha S, Chant D, McGrath J. A systematic review of mortality in schizophrenia: is the differential mortality gap worsening over time? Arch Gen Psychiatry. 2007; 64(10):1123-31.

22. Ringen PA, Engh JA, Birkenaes AB, Dieset I, Andreassen OA. Increased mortality in schizophrenia due to cardiovascular disease - a non-systematic review of epidemiology, possible causes, and interventions. Front Psychiatry. 2014; 5:137

23. Brauer R, Douglas I, Smeeth L. The association between antipsychotic agents and the risk of myocardial infarction: a systematic review. Br J Clin Pharmacol. 2011; 72(6):871-8.

24. Hennessy S, Bilker WB, Knauss JS, Margolis DJ, Kimmel SE, Reynolds RF, et al. Cardiac arrest and ventricular arrhythmia in patients taking antipsychotic drugs: cohort study using administrative data. BMJ. 2002; 325:(7372):1070.

25. Bresee LC, Majumdar SR, Patten SB, Johnson JA. Prevalence of cardiovascular risk factors and disease in people with schizophrenia: a population-based study. Schizophr Res. 2010; 117(1):75-82. 